Supporting Information

\title{
Thermo-Responsive Collagen/Cell Penetrating Hybrid Peptide as Nanocarrier in Targeting-Free Cell Selection and Uptake
}

\author{
Myungeun Oh, Chloe Hu, Selina F. Urfano, Merlyn Arostegui, Katarzyna Slowinska* \\ Department of Chemistry and Biochemistry, California State University Long Beach, \\ Long Beach, California 90840
}

\section{Supplemental Figures}


A

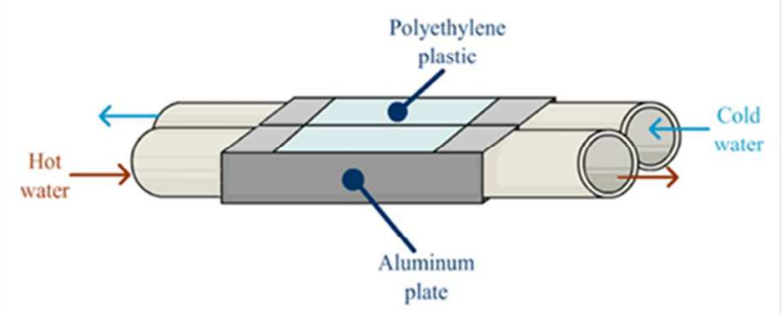

B

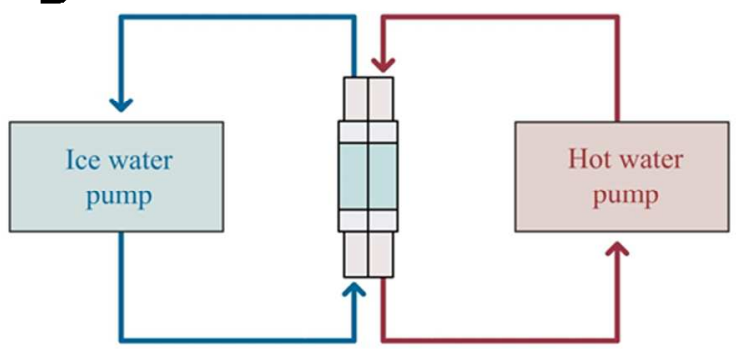

Figure S1. (A) Schematic design of the device used to generate 2D temperature gradient (B) scheme of cooling/heating circulation mechanism. 

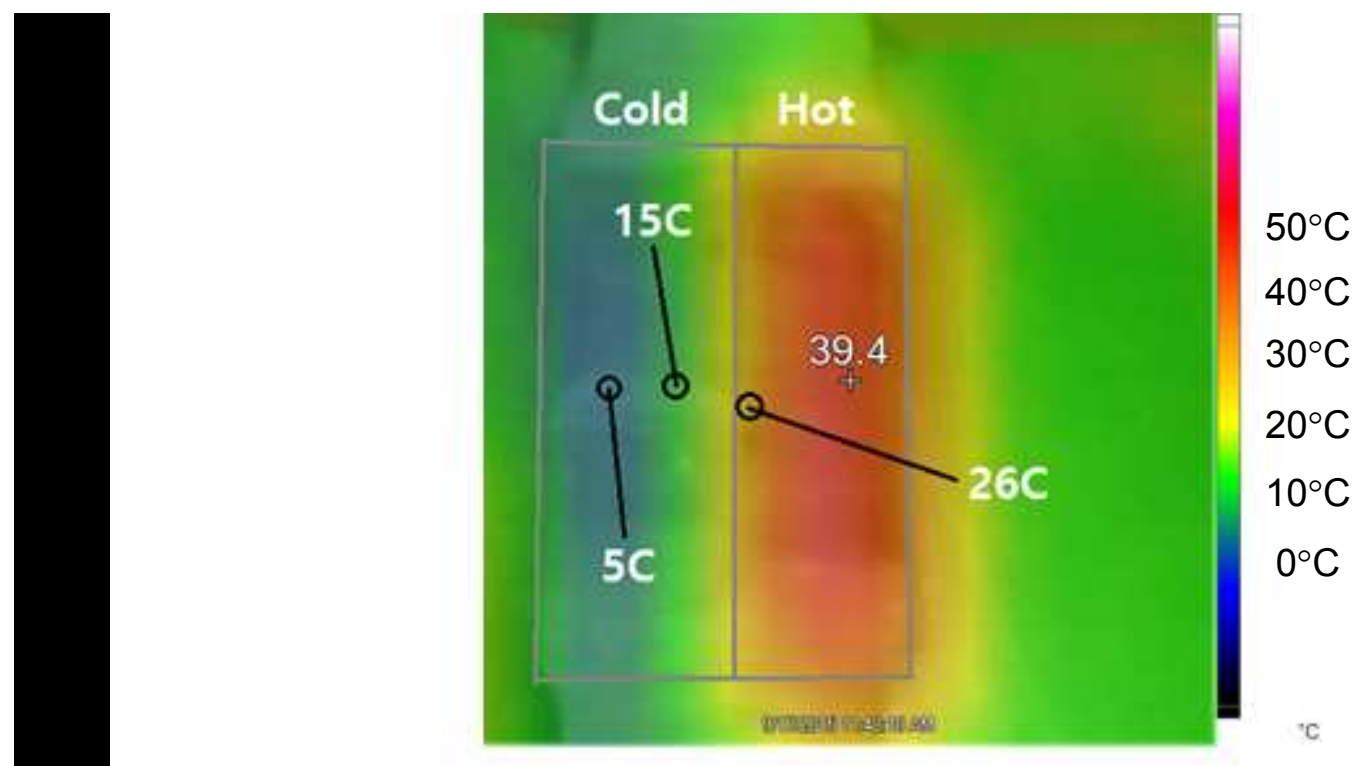

Figure S2. Surface temperature distribution picture of cover slip position on the device used to generate the temperature gradient. 


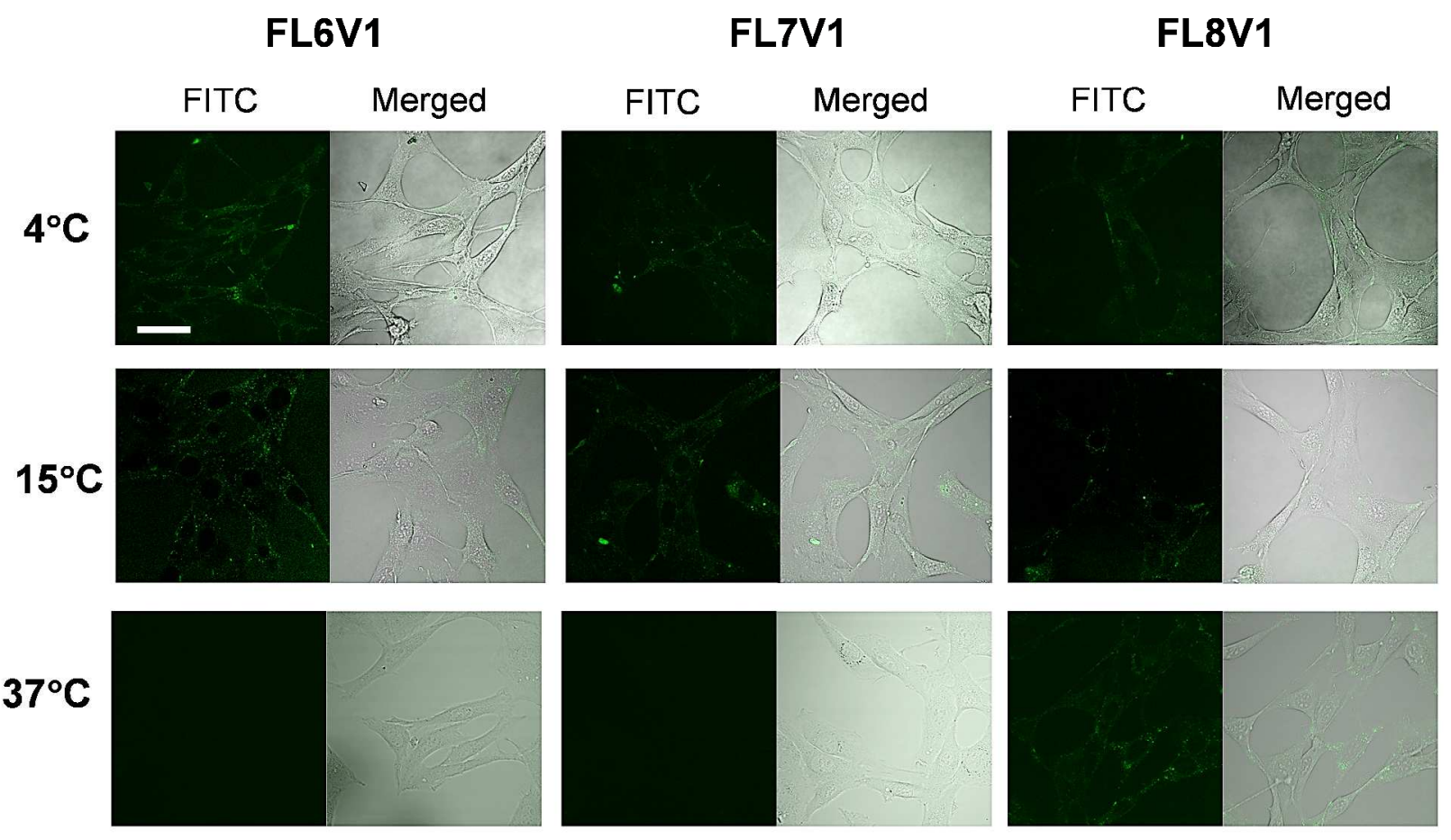

Figure S3. Variable temperature study. Confocal microscopy of $3 \mathrm{~T} 3$ fibroblasts incubated with FL6V1, FL7V1 and FL8V1 $(15 \mu \mathrm{M})$ for $15 \mathrm{~min}$ at different temperatures. Bar represents $20 \mu \mathrm{m}$. 


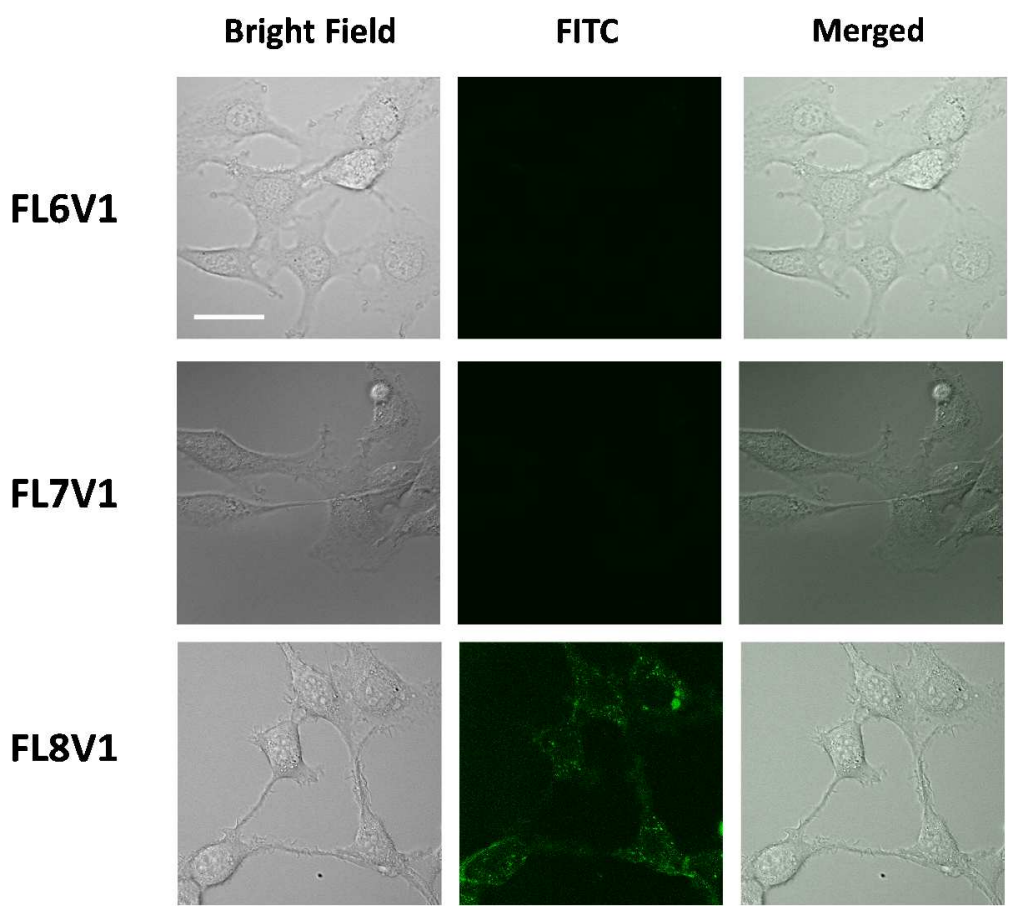

Figure S4. Long time incubation study. Confocal microscopy of 3T3 fibroblasts incubated with FL6V1, FL7V1 and FL8V1 $(15 \mu \mathrm{M})$ for $120 \mathrm{~min}$. Bar represents $20 \mu \mathrm{m}$. 

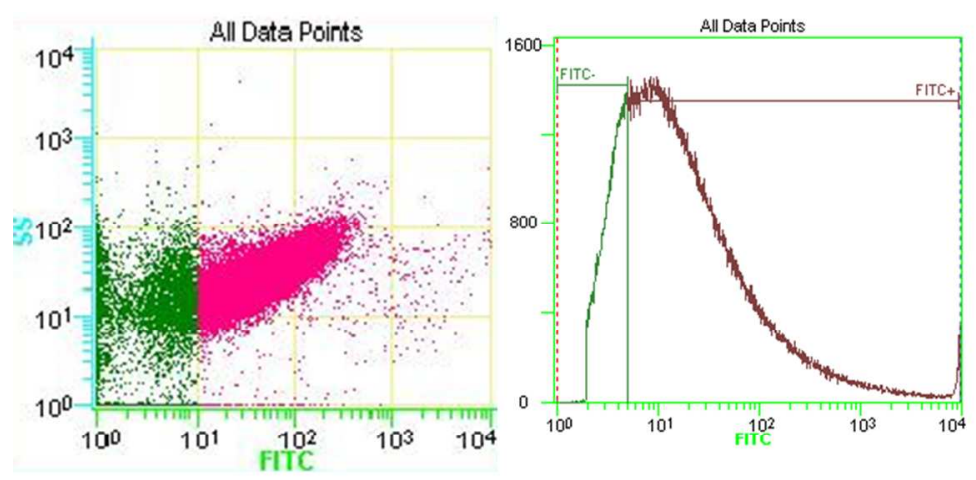

\section{FL8V1}

\begin{tabular}{|lrrrrl|}
\hline & FL1 & FL1 & FL1 & Pct & \\
Region & Mean & HPCV & CV & Gated & Count \\
\hline FITC- & 3.56 & $19.61 \%$ & $24.04 \%$ & $19.19 \%$ & 95,964 \\
FITC+ & 181.83 & $156.86 \%$ & $\# \# \#$ & $80.81 \%$ & 404,036 \\
\hline
\end{tabular}
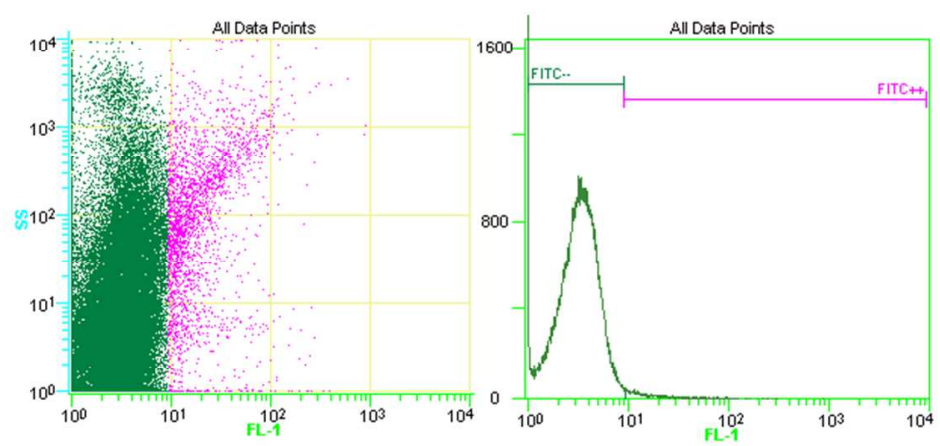

FL7V1
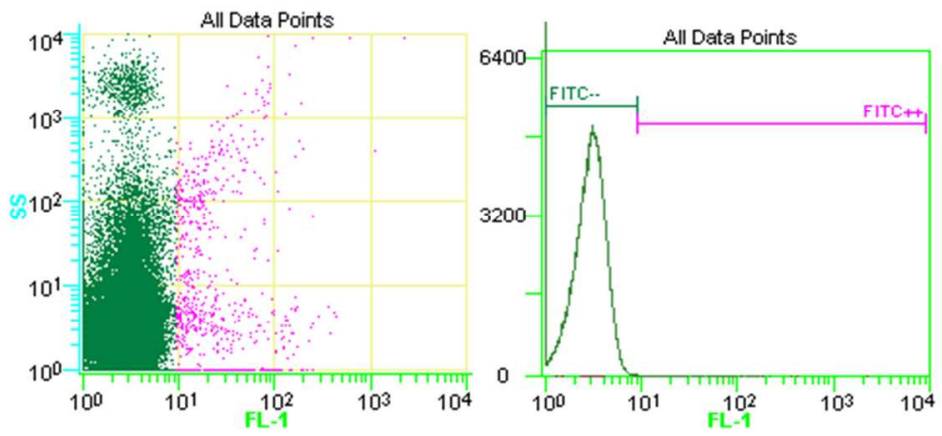

FL6V1

\begin{tabular}{|c|c|c|c|c|c|}
\hline Region & $\begin{array}{c}\text { EV } \\
\text { Mean }\end{array}$ & $\begin{array}{c}\text { EV } \\
\text { HPCV }\end{array}$ & $\begin{array}{c}I \mathrm{ml} \\
\times 1000 \\
\end{array}$ & Count & $\begin{array}{l}\text { Pct } \\
\text { Total }\end{array}$ \\
\hline TC-- & 13.25 & $23.22 \%$ & 18,388 & 128,021 & $97.86 \%$ \\
\hline =ITC++ & 143.22 & $49.10 \%$ & 401 & 2,794 & $2.14 \%$ \\
\hline
\end{tabular}

Figure S5. Flow cytometry (FITC channel and Side Scatter) of 3T3 fibroblasts incubated with FL6V1, FL7V1 and FL8V1 $(15 \mu \mathrm{M})$ for $15 \mathrm{~min}$ at $37^{\circ} \mathrm{C}$. 

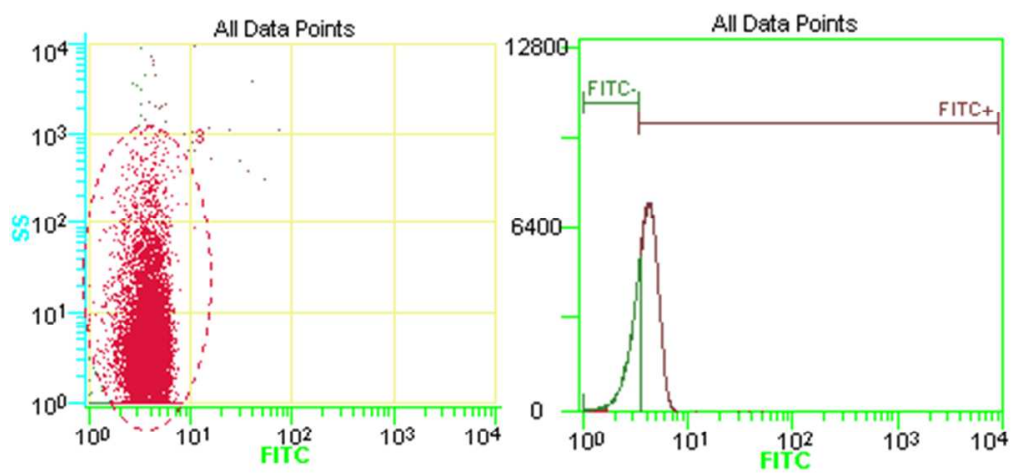

\section{FL8V1}
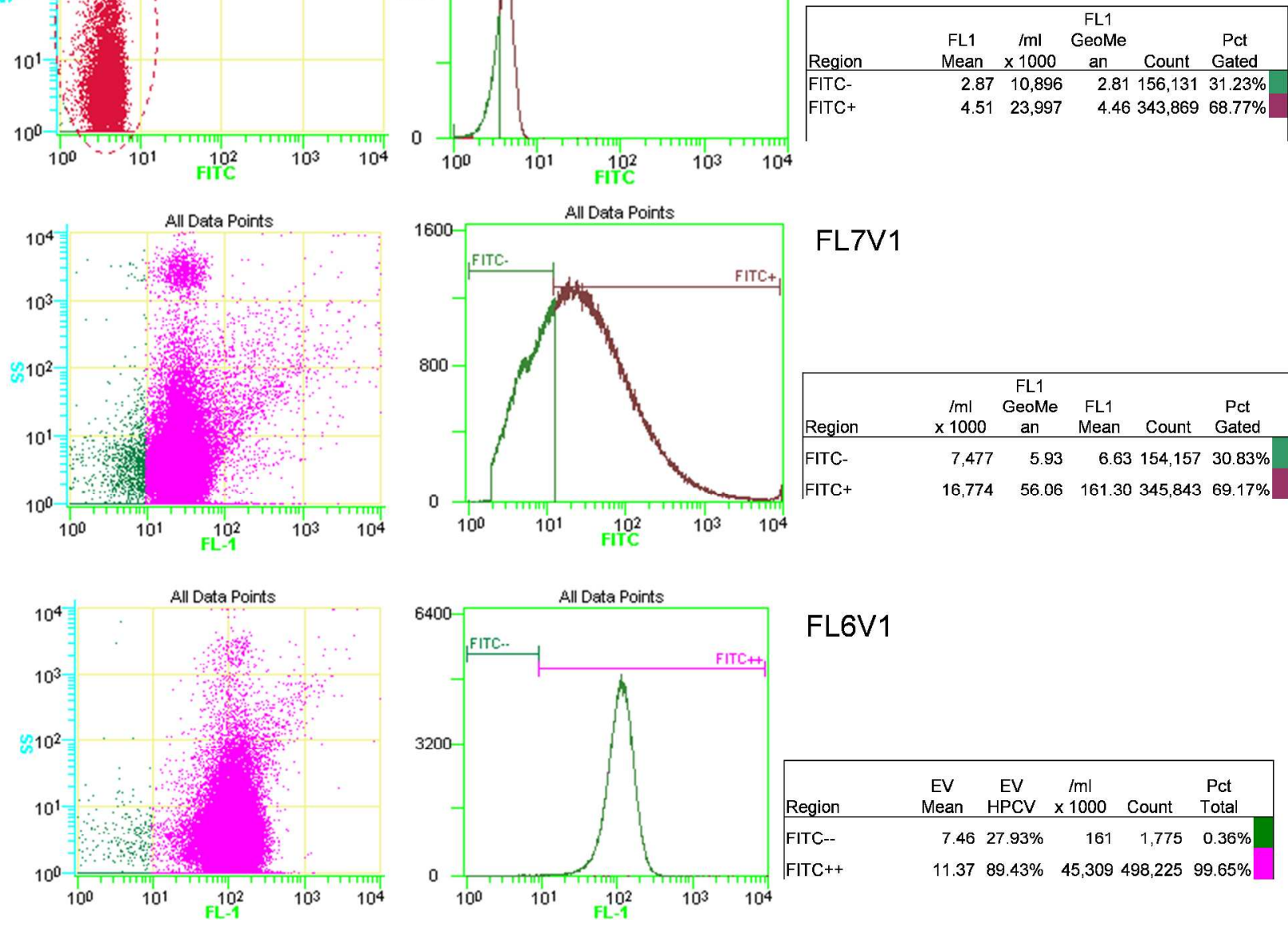

\section{FL6V1}

Figure S6. Flow cytometry (FITC channel and Side Scatter) of 3T3 fibroblasts incubated with FL6V1, FL7V1 and FL8V1 $(15 \mu \mathrm{M})$ for $15 \mathrm{~min}$ at $15^{\circ} \mathrm{C}$. 
FL8V1
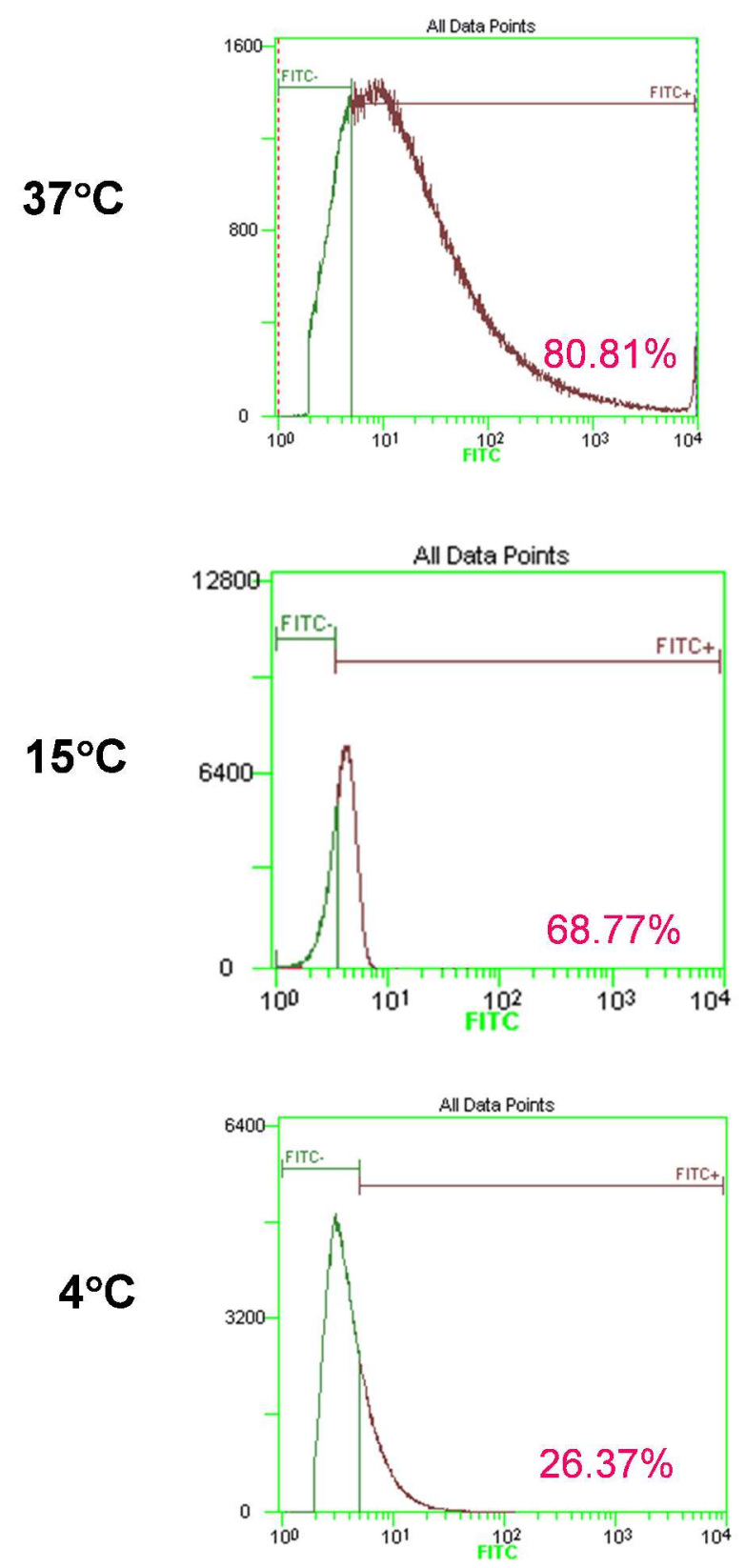

FL6V1
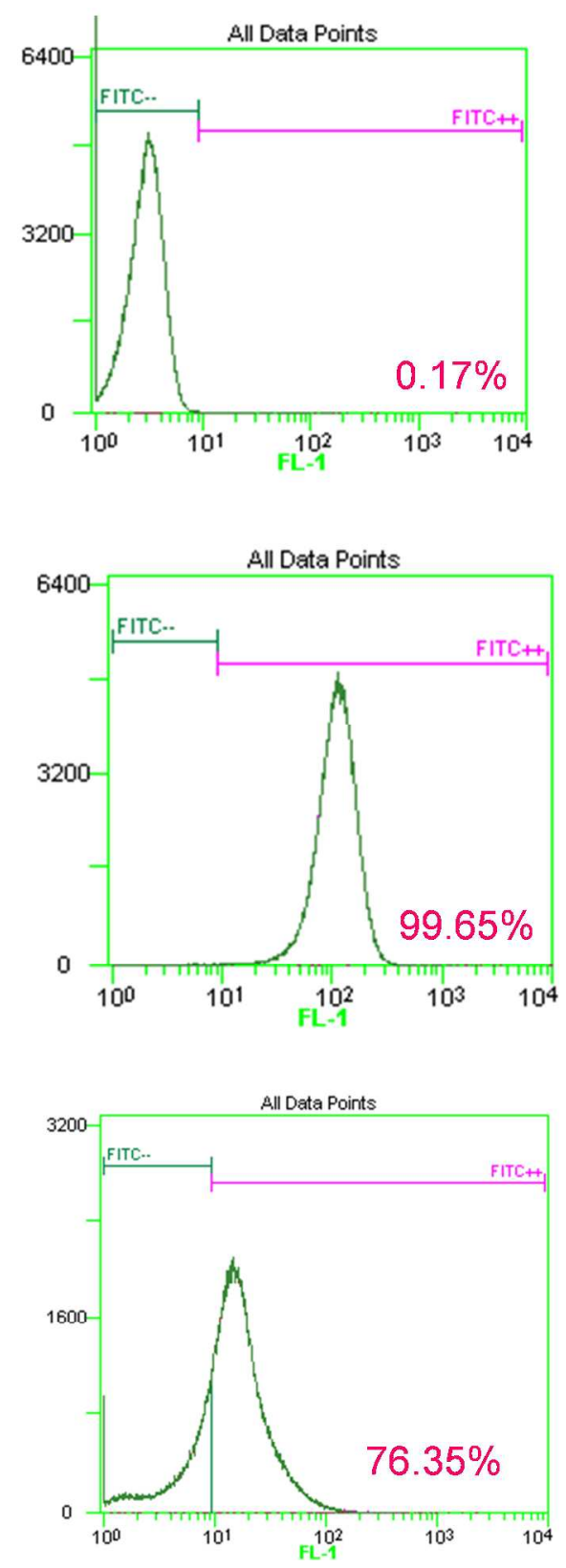

Figure S7. Flow cytometry of 3 T3 fibroblasts incubated with FL6V1 and FL8V1 $(15 \mu \mathrm{M})$ for 15 $\min$ at 4,15 , and $37^{\circ} \mathrm{C}$. 